\title{
Throwing the Baby Out With the Bathwater: Can the Military's Role in Global Health Crises be Redeemed?
}

\author{
Frederick M. Burkle, Jr., MD, MPH, DTM
}

Section Editor for Humanitarian Affairs, Prehospital and Disaster Medicine; Harvard Humanitarian Initiative, Harvard University, Cambridge, Massachusetts USA; and Woodrow Wilson International Center for Scholars, Washington, DC USA

Keywords: global health crises; hospital ships; military humanitarian assistance

Abbreviations:

DoD: Department of Defense

USAID: US Agency for

International Development

Online publication: March 14, 2013

doi:10.1017/S1049023X13000162

\begin{abstract}
For decades, military humanitarian assistance programs have avoided empirical scrutiny, leaving researchers, the humanitarian community and decision makers without proof of outcome. This Editorial highlights the findings of three major studies that disclose deficits in the quality of the performance and reporting of humanitarian missions, and offer guidance for change. The author suggests that, contrary to current plans to limit the military's role in humanitarian assistance, emerging crises actually increase civilian security risks and that it is time for a new partnership of military and civilian humanitarian resources to evolve in the interest of human security.
\end{abstract}

Burkle FM. Throwing the baby out with the bathwater: can the military's role in global health crises be redeemed?. Prehosp Disaster Med. 2013;28(3):197-199.

In this issue, Derek Licina's research analysis of US hospital ship deployments from 2004-2012 has proved timely. ${ }^{1}$ He confirms what many have suspected for decades: while centered on promoting global health foreign policy initiatives, the stated accomplishments and achievements of hospital ship deployments are more anecdotal than factual. For too long, the military has ignored efforts by academia, the humanitarian community and their own officers and staff, especially those in the medical corps, to properly document and report outcome data in favor of Command mandates to singularly "show results" that their humanitarian projects are "winning the hearts and minds." If there are reasons for these actions, I argue they are political in nature.

Many civilian educators and researchers who first embraced the military's role and offered them education and training looked forward to documenting the outcome and value of their many global missions. The bulk of training was focused on field epidemiology and assessment efforts that, for the most part, have come to naught. In an era that demands evidence-based decision making, the stonewalling of analyses many have witnessed in assessing military-led projects does not make sense, nor is it justifiably limited under claims of data being "classified." While military medicine has published manuals on guidelines for measures of effectiveness, this effort has not been translated from the field to the peerreviewed literature nor added to the evidence base for humanitarian operations. When descriptive articles are published, the data presented is not open to the usual scientific empirical scrutiny. For example, hospital ship beneficiaries are routinely tallied as "patient encounters" for each diagnosis and every procedure performed, not as one patient visit, so results are inflated up to seven to nine times those that other humanitarian organizations conventionally report. Absolute numbers of procedures performed are reported without disaggregation as to type, giving the impression that the inordinate number of surgeries is life saving, when in truth the majority are found to be dental extractions. Motives favor a "military culture" designed to actively promote the contribution of the mission and recognition of the work of each health service (eg, nursing, outpatient clinics, dental, laboratory) and the deployed platform itself. Indeed, the US Congress, which rates the Department of Defense (DoD) as the most effective government agency, regularly cites these humanitarian missions as examples of great success. In contrast, the US Agency for International Development's (USAID's) detailed accounts reflect the "uncomfortablebut-real" ground truths that are too often ignored or brushed aside. As a result, everyone suffers, as does the accountability and transparency that is historically valued in humanitarian aid. As Licina notes, both participants and beneficiaries deserve better. 
The authors of a second document, the 2012 Kaiser Foundation's US DoD and Global Health study, ${ }^{2}$ are equally skeptical of the massive budgets, utility, and validity of programs that each and every major component of the military sees as its own global health initiatives. The study claims that initiatives "may or may not be well-coordinated, monitored and evaluated, or consistently integrated into the broader DoD strategic and military plans." 2 There is no one DoD global health budget, and no one knows what each component of the military and the Combatant Command's (ie, Pacific Command, European Command, Africa Command, etc.) global health budgets is about. Programs and projects are poorly vetted, secretive, competitive with other Commands, lack oversight, and are primarily documented in a descriptive fashion only. This leaves DoD's global health-related efforts both "complex and diffuse." A 2012 GAO report on managing the military's efforts in humanitarian and development assistance found similar concerns highlighting "major coordination, poor data management, limited program evaluations, and limited program guidance" among the existing challenges. ${ }^{3}$ From a diplomatic viewpoint, Brian Atwood, former Director of the USAID, has written for the National Defense University that while these "activities can enhance the image of the Armed Forces," military members are inhibited by the fact that DOD personnel are "not trained to work with foreign cultures and languages, especially at the civil society level; they are not civilians and thus have a harder time relating to civil society; and, regardless of training, their knowledge of the long-term development mission is limited."

More than at any other time in our country's history, US foreign policy today is driven by health initiatives, and health initiatives are driving foreign policy. ${ }^{5}$ The military has renamed many "humanitarian" projects under the mantle of "health diplomacy." These unbridled initiatives are without strategic plans or policies that should, with the global health crises and challenges facing the world today, be highly coordinated and integrated with those of global stakeholders. Hospital ships are but one of many health-related deployment platforms, the value and cost-effectiveness of which are not being vetted, debated, or discussed within the global health community. At a time of global financial constraints that sap funding for critical global health programs worldwide, these ship missions are government-centric, are deployed in competition with China, Russia, Spain and Cuba, and ignore measures of effectiveness or "efforts to understand how DoD fits into the larger landscape of US and international engagement on global health." 2 The Kaiser Foundation report adds that "misunderstandings and difficulties" in defining DoD's global health programs are "differences in approach, organizational culture, and vocabulary between DoD and others working on global health." These activities continue despite DoD's "failing to give due consideration to the methods and principles that define successful global health programs even as it has increased its attention to such activities."

If I had the name of or access to the one person in DoD who admitted to being "in charge" of these global health decisions, my first impulse would be to shake that person's lapels and ask, "Just what are you thinking?" For one, DoD has and will have, even in the contested 2013 budget, more funding for global health than any other authority, domestically and globally. Two, the present decision to sideline "stability operations" (the current pseudonym for humanitarian operations) and nation building and pay "greater attention to Asia" may be too hasty. Yes, too hasty! The DoD never "reexamined or clarified"2 its global health activities before it summarily dismissed them...that is confusing! Does one then assume that these missions, especially hospital ship deployments, will continue? ... But to what end? The global health community needs clarification.

I say "too hasty" because the armed forces may not be fully aware that the taxonomy of conflict is undergoing its own drastic transition. The imposed changes and operational impact on the future of humanitarianism are massive. While declared wars are at their lowest in over a century, unconventional warfare is here to stay. Despite media emphasis on military casualties, it is safer to be in uniform. Sixty to 70 percent of those killed are civilians. Increasingly, the established humanitarian community is not working in war zones but rather in crime zones where organized armed violence includes fights over ownership and control of rare earth and natural resource extraction, high-seas piracy, armed robbery, drug trafficking, and arms trading. More than half of the UN Peacekeeping Forces deployed globally are in emergency situations where natural resources play a major role in the conflict. More humanitarian workers have been killed than peacekeepers, and many face kidnappings, daily violent threats, taxation, and restriction of access to the populations they were sent to serve. The humanitarian community has not been successful in mitigating the rise in civilian deaths, but neither has the military. However, when working together, civilian and military assets do better. The many who witnessed the 1992 Operation Provide Comfort when the US-led Coalition of militaries from 13 countries furnished security, communications, heavy lift, and logistical assistance to the humanitarian organizations assisting the Kurds in the hills of Northern Iraq were optimistic that this model would continue. It was the military's finest hour. The humanitarian community observed that "for the most part the military was considered to have been an ally in the struggle to provide security and assistance." ${ }^{6}$ However, when the military unilaterally decided it should have a larger role in humanitarian aid, this success was short lived and the model was never repeated. Painfully, the blurring of military "stabilization strategies" and humanitarian operations led to two of the most dangerous decades for humanitarian aid workers.

Be that as it may, there is a potential opportunity here that must not be lost. The problem of rising civilian deaths has not been solved, let alone sufficiently addressed; it is not the time to turn our backs on them morally, politically and militarily. The current transition of the military away from a humanitarian role must be reconsidered and "paused" while a proper vetting is carried out based on information relevant to current conflicts, future crises triggered by rapid unsustainable urbanization, biodiversity losses, massive population displacement from climate change, and global land grabbing over scarce resources in food, water and energy. All of these events will dominate both conflict and humanitarian aid for the coming decades; this clearly requires military resources to ensure "human security." The armed forces may have a major role that they, thus far, are not cognizant of. The question should be whether the US military and the militaries of all nations can take this current transition time to reflect on studies published on their behalf, and both relearn and recapture a partnership within the broader global community they have not yet contemplated. 
References

1. Licina D. Hospital Ships Adrift? Part 1: A systematic literature review characterizing U.S. Navy hospital ship humanitarian and disaster response from 2004 to 2012. Prehosp Disaster Med. In press.

2. Kaiser Family Foundation. U.S. Global Health Policy, the U.S. Department of Defense and Global Health Report. U.S. Global Health Policy Program. Publication Number 8358, http://www.kff.org/globalhealth/8358.cfm. Published February 10, 2012. Accessed December 2, 2012.

3. United States Government Accountability Office (GAO). Humanitarian Aid Development Assistance: Project evaluations and better information sharing needed to manage the military's efforts. GAO-12-359. Report to Congressional Committees. http://www.gao.gov/assets/590/588334.pdf. Published February 2012. Accessed December 2, 2012.

4. Atwood JB. Elevating development assistance. PRISM. 2010;1(3):3-11.

5. Feldbaum H, Michaud J. Health diplomacy and the enduring relevance of foreign policy interests. Policy Forum. PLos Medicine. 2010;7(4):1-6.e1000226.

6. Anonymous. Operation Provide Comfort After Action Report to International Services, American Red Cross. Washington, DC. April, 1992 